\title{
REVIEW
}

\section{Therapeutic implications of sex differences in asthma and atopy}

\section{Osman}

Arch Dis Child 2003;88:587-590

Clear sex differences exist in asthma and atopy with a preponderance of boys before puberty. There is a reversal of this sex ratio during puberty with girls having more asthma and atopy throughout the reproductive years. Elucidating the reasons for the switch in the sex ratio should provide fresh insights into asthma and atopy with a real prospect of novel therapies for these troublesome diseases. The challenge is to match the epidemiology and physiology with the accumulating scientific knowledge on gender differences in immune responses. Hormonal changes have been implicated in the reversal of the sex ratio. Testosterone is an immunosuppressant and is likely to be protective, while female sex steroids are proinflammatory and will increase the susceptibility to atopy. Modified so as to be non-virilising/feminising, sex steroids could therefore play a useful part in modulating the immunological and inflammatory processes that underlie asthma and other allergic disorders, complementing the currently used glucocorticoid derived steroids.

Correspondence to: Dr M Osman, Clinical Lecturer in Child Health, Department of Child Health, Aberdeen AB25 2ZD, Scotland, UK; m.osman@abdn.ac.uk

Accepted

19 October 2002
B eyond the obvious male/female divergence of physical characteristics during puberty there are intriguing and potentially informative sex differences in the expression and underlying mechanisms of a range of health problems. These include asthma, arthritis, migraine, depression, diabetes, epilepsy, and neurodevelopment. ${ }^{12}$ Sex differences are evident in mortality and morbidity figures, prescribing patterns, and in hospital admissions. ${ }^{2}$ These differences may be altered with the onset of puberty. ${ }^{1}$ Unravelling these patterns of sickness and health may contribute to understanding the processes that initiate and perpetuate disease, leading to disease prevention and improved therapy.

\section{SEX AND DISEASE}

In this context it is important to distinguish between biological determinants of health related sex differences from sociocultural determinants. Differences in biological risk are illustrated by sex differences in critical medical illness. In a population matched for sex distribution, endotracheal intubation for acute respiratory failure, a procedure in which there is usually little subjective variation, was more often required in boys. This was most noticeable in cases of upper airway infection and bronchiolitis. ${ }^{3}$ However, in the same population there was an excess of deaths in girls arising from multisystemic inflammatory or vasculitic syndromes and immunodeficiency complicated by pneumonia.

Sociocultural explanations for biodiversity include gender specific illness behaviour or symptom perception. A greater concern and attention to health may result in lower mortality, while the reverse may result in poorer utilisation of health resources and hence poorer health outcomes. ${ }^{1}$ The interactions among biological and social factors in disease expression are illustrated in the case of juvenile onset insulin dependent diabetes. Before puberty, boys are at a higher risk for hypoglycaemia, while after puberty, girls are at an increased risk for diabetic ketoacidosis. ${ }^{4}$ Biological and sociocultural factors are both responsible for this pattern.

\section{REPORTED SEX DIFFERENCES IN ASTHMA AND ALLERGY}

Epidemiological studies, of both incidence and prevalence, have reported a male predominance of asthma and atopic conditions before puberty and a female predominance after puberty. ${ }^{56}$ The National Child Development Study in the UK observed a male predominance in the incidence of reported asthma before 16 years of age with a reversal of the sex ratio thereafter. ${ }^{7}$ Similar findings have been reported for the prevalence of wheeze and asthma, with higher rates in women through the reproductive years. ${ }^{28}$ The influences of gender are also seen for hospital admissions, with more boys admitted before puberty and a gender reversal evident post-puberty. The sex differences in admission rates are of a magnitude that is easily and consistently demonstrable. For example, this pattern is noticeable in the annual admission rate for asthma in all hospitals in Scotland (fig 1). The hospital admission data probably reflect more than predisposition and suggest possible differences in severity. In asthma cases followed prospectively from childhood, severity decreased during adolescence only among males. ${ }^{10}$ Cross sectional studies also show that females are more likely to develop late onset and persistent wheeze. ${ }^{11}$

The prevalence of reported hay fever is greater in prepubertal boys, with a change to a female predominance in adolescence. ${ }^{212}{ }^{13}$ Girls have higher reported eczema prevalence in early childhood; this gender difference becomes more noticeable with time. ${ }^{11}$

Abbreviations: BHR, bronchial hyperresponsiveness; SLE, systemic lupus erythematosus 


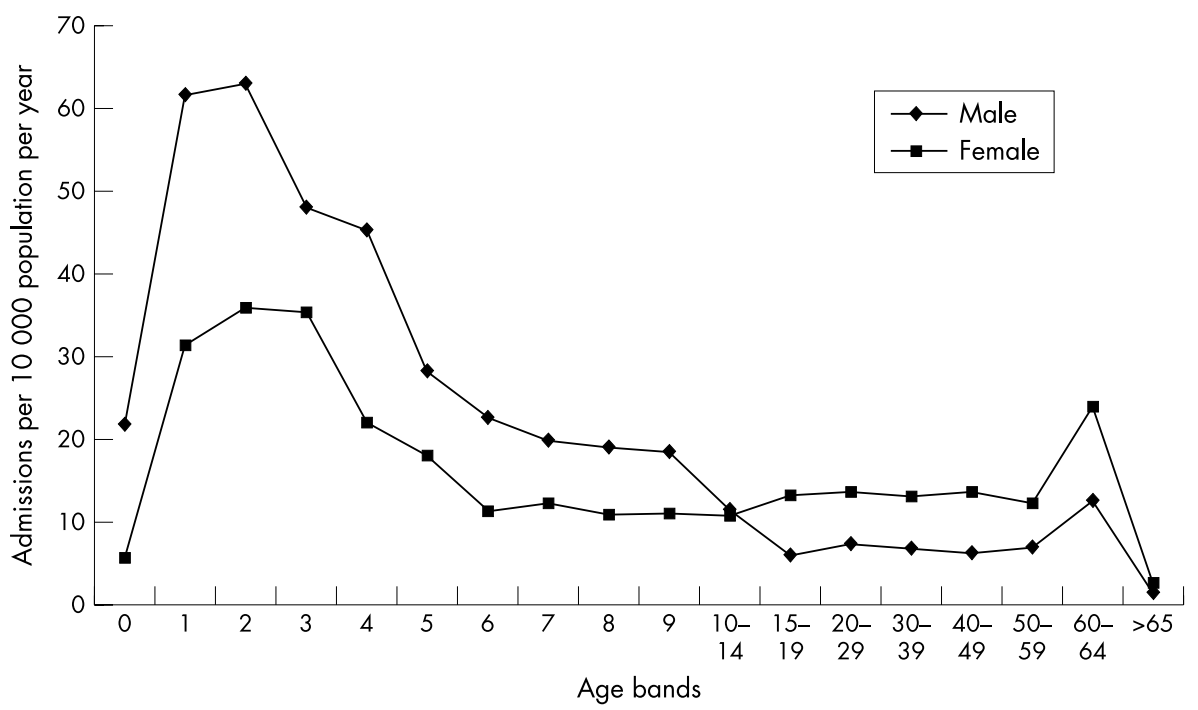

Figure 1 Asthma admissions (ICD J45) for all hospitals in Scotland from April 2000 to April 2001 by selected age groups and sex. (Source: Scottish Morbidity Data Information and Statistics Division, Common Services Agency, NHS Scotland)

\section{CURRENT AND ALTERNATIVE PERSPECTIVES ON SEX DIFFERENCES IN ASTHMA AND ATOPY}

Current explanations include sociocultural influences on diagnostic labelling or sex differences in lung development and function.

Sociocultural factors have been suggested to lead to underdiagnosis of asthma in younger girls. ${ }^{14}$ The phenomenon of what has been termed the "Yentl syndrome", where girls and young women are treated differently by the medical profession despite an equal disease severity to males, has been invoked to explain underdiagnosis of asthma in girls. ${ }^{14}$ Gender differences in perception and reporting threshold of symptoms may also influence detection and diagnosis of disease. This explanation remains speculative and does not address the reversal of the sex ratio in the transition from childhood to adulthood.

There is evidence that airway development is different between the sexes, with a relative slow pace of airway development compared with growth of lung volume in males, so called dysnaptic lung growth. ${ }^{15}{ }^{16}$ In females there is proportionate growth of airways to lung volume and as a consequence greater air flow rates at fixed proportions of total lung capacity. Boys have lower expiratory air flow rates at all comparable lung volumes. ${ }^{15}$ As the likelihood of symptoms of airway obstruction will be influenced by baseline values, this places the males at a disadvantage, particularly with viral induced wheeze. This sex difference reverses at puberty with an acceleration of all indices of lung function in males. ${ }^{15} 16$ The fact that these sex related differences in the growth of lung function has not been confirmed by morphometric studies highlights the influence of the rapidly expanding chest wall and increasing strength of respiratory muscles in the male. ${ }^{17}{ }^{18}$ However, it is unlikely that asthma and wheezy disorders are fully explained by structural or functional airway sex differences as inflammatory responses within the airway wall are also involved in the genesis of airway obstruction. Factors other than lung function and growth, and in particular sex related differences in immune response, are at work during puberty, as clearly indicated by the gender switch in hay fever and the increasing expression of eczema in females.

Atopic diseases, including asthma are characterised by chronic immune mediated inflammation, initiated and perpetuated by CD4+ T helper cells. Th1 and Th2 phenotypes are characterised by the secretion of interferon $\gamma$ and interleukin 4 , respectively, and in atopic diseases Th2 responses predominate. ${ }^{19}$ Although not all asthma is atopic and not all atopy leads to asthma, much of childhood asthma has an allergic component as highlighted by the association with raised IgE, skin reactivity, and bronchial hyperresponsiveness. Thus an underlying immune basis for the sex differences in asthma and atopy during and after puberty must also be considered. Biological markers of asthma and allergy encourage this consideration as they follow a similar pattern to the epidemiology.

\section{SEX AND BIOMARKERS OF ATOPY}

In childhood boys have increased non-specific bronchial hyperresponsiveness (BHR) in comparison to girls. ${ }^{20}{ }^{21}$ In contrast, women have increased BHR even when gender differences in baseline forced expiratory volume in one second $\left(\mathrm{FEV}_{1}\right)$ are taken into account. ${ }^{22}$ These features have also been confirmed in a cohort of children followed to early adulthood, with female sex clearly identified as a risk factor for early adult onset BHR. ${ }^{23}$

Skin reactivity to inhalant allergens is higher in young males and remains so for most of early adult life, although the male bias appears to reverse in later adult life. ${ }^{20} 2324$

The higher serum IgE levels found in young males also becomes less noticeable with increasing age. ${ }^{25} 26$

\section{SEX HORMONES AND ATOPY}

The reversal of the male/female prevalences of asthma and other atopic conditions at puberty strongly suggests a role for sex hormones. The known influences of the menstrual cycle on asthma support a role for female sex hormones in the changing expression of atopy and asthma during puberty and adolescence. In the $30-50 \%$ of women so affected deterioration usually occurs in the premenstrual phase, although exacerbations can also occur in the ovulatory phase. ${ }^{27}$ Both BHR and skin reactivity increase during the menstrual cycle, peaking in the luteal and follicular phase respectively, just at the time when sex steroids are at their highest levels. ${ }^{28}{ }^{29}$

Although the immunomodulatory properties of sex steroids have been known for many years in the autoimmunity field, this knowledge has seldom been applied to asthma and allergy although there is some evidence of their contribution to relevant underlying mechanisms. Oestrogen enhances, while testosterone inhibits eosinophil release. ${ }^{30}$ Testosterone is a powerful inhibitor of histamine. ${ }^{6}$ Oestrogen augments while testosterone and tamoxifen, an oestrogen antagonist, inhibit mast cell degranulation. ${ }^{31}$ 


\section{SEX HORMONES AND AUTOIMMUNITY}

To understand the mechanisms underlying gender predispositions and the influences of sex hormones on the expression of atopic disease, it is instructive to draw a parallel with their known influence on autoimmunity. ${ }^{32} 33$ Sex differences have been clearly shown in the expression of autoimmune diseases, with females comprising approximately $75 \%$ of all cases and with notable shifts in this risk over a life span. For systemic lupus erythematosus (SLE) the female:male sex ratio is approximately 2.5:1 in prepubertal children, 10:1 during the reproductive years, falling to 2.5:1 again post-menopause. ${ }^{32}$ Associations have been observed between low testosterone levels and rheumatoid arthritis in male patients, ${ }^{34}$ and abnormalities of oestrogen metabolism in women with SLE. ${ }^{35}$ Patients with Klinefelter's syndrome also have a greater incidence of SLE and myasthenia gravis. ${ }^{32}$

Direct evidence of the modulatory influence of sex hormones comes from animal models of SLE, Hashimoto's thyroiditis, and streptococcal cell wall induced autoimmune arthritis. Laboratory studies show that female animals are strikingly more susceptible to experimental models of autoimmunity. ${ }^{32}{ }^{36}$ Diseased animals show improved survival when treated with antioestrogens such as tamoxifen, with antioestradiol antibodies or testosterone. ${ }^{37}$ However, supplementation with oestrogens accelerates and exacerbates disease. $^{32} 38$

\section{SEX HORMONES AND IMMUNE RESPONSES}

Immune diamorphism, the term given to differences in immune responses and regulation between the sexes, is apparent in the more notable humoral and cellular response present in women. ${ }^{339}$ Women exhibit stronger antibody responses to immunisation and infection ${ }^{39}$ and have higher levels of all antibody classes with the exception of IgE. ${ }^{33}$ Immune diamorphism is primarily a result of the immunomodulatory effects of sex hormones. ${ }^{33}{ }^{36}{ }^{40}$ Female and male sex hormones influence $\mathrm{T}$ cell populations, the production of specific antibodies, and proinflammatory mediators. ${ }^{38}$ In general female sex steroids enhance immune responses in both physiological and pathological states, whereas testosterone dampens inflammatory responses. ${ }^{32}$ Endogenous androgens appear to have stronger immunosuppressive effects than endogenous glucocorticoids. ${ }^{39}$

Receptors for sex steroids have been identified on lymphocytes, monocytes, and mast cells. ${ }^{41}{ }^{42}$ Androgen metabolism has been shown in alveolar macrophages with conversion of androstenedione into the more potent testosterone and dihydrotestosterone..$^{43}$ Oestrogen and progesterone receptors have been found in significant numbers on mast cells isolated from the upper airways. ${ }^{41}$

The in vitro effects of physiological concentrations of oestrogen and testosterone on the antigen non-specific differentiation of human peripheral blood monocytes (PBMC) have been examined. ${ }^{44}$ In cultures of PBMC from healthy individuals, oestrogen enhanced proliferation responses to pokeweed mitogen by $46 \%$, whereas testosterone inhibited responses by $36 \%$ from baseline. Oestrogens increase B cell response, both in vitro and in vivo, while progesterone and androgens depress antibody production. ${ }^{39}$ The observation that the effects of sex steroids on lymphocyte maturation and proliferation are the same for both male and female cells studied in vitro suggests that these effects are not due to inherent genetic differences but rather to the hormonal milieu in which they are placed. ${ }^{45}$

Oestrogen directly regulates the interferon $\gamma$ gene and short exposure to physiological levels increases expression. ${ }^{46}$ Oestrogen is understood to have a biphasic dose-response, with higher levels promoting Th2 responses and lower levels a Th1 response. $^{33}$ Progesterone has been shown to stimulate interleukin 4 production and promote the development of human Th2 cells. ${ }^{47}$

\section{IMPLICATIONS FOR THERAPY}

These sex differences are of more than purely biological interest. The anti-inflammatory effects of testosterone and proinflammatory effects of female sex steroids at physiological levels raises the prospect of putting this knowledge to therapeutic use, providing sex steroid effects on the reproductive system could be separated from their immunomodulating properties. Such possibilities should be an incentive for research into gender biodiversity. The strategies of drug development include modification of sex steroids, gender specific treatment, and organ specific therapy.

Androgens with anti-inflammatory properties but without the virilising effects form one avenue of enquiry. Further elucidation of the androgen signalling involved in modifying immune responses could result in novel therapies downstream of this pathway. In a similar fashion understanding female sex steroid actions, interactions, and signalling pathways could be used to develop agents which interfere with the process at a level that would not undermine their general activity elsewhere in the body. Such tissue specific treatment is already underway in the treatment of breast cancer with agents such as tamoxifen.

The virilising effects of androgens in females are an obvious concern and a limitation recognised at an early stage in autoimmune research. There are, however, adrenal androgens, such as dihydroepiandrosterone (DHEA), that are shared between males and females and that have fewer virilising effects. In a prospective open labelled uncontrolled study 50 female patients with mild to moderate SLE were treated with DHEA 50-200 mg/day. ${ }^{48}$ Levels of DHEA and testosterone increased, while disease activity by report and assessment using standardised instruments decreased. Significantly less prednisolone was used and improvements were sustained over the trial period of a year. Thirty four patients completed treatment for six months, and 21 for one year. Acneiform dermatitis, a recognised side effect of androgens, was the commonest reason for discontinuing therapy.

An alternative approach is gender tailored therapy. Male rheumatoid arthritis patients with low testosterone levels have been treated with testosterone. Restoring testosterone to normal levels was accompanied by an increase in the CD8 T cells with a lowering of the CD4:CD8 ratio and a decreased IgM rheumatoid factor. Significant increases in testosterone resulted in a clinically significant reduction in the number of affected joints and minimised the need for non-steroidal antiinflammatory drugs. ${ }^{49}$ Males with Klinefelter's syndrome and with Sjogren's syndrome or SLE have clinical remission of their autoimmune disease and a reduction in associated inflammatory mediators and antibodies on being treated with replacement testosterone..$^{50}$

Another approach to reduction of systemic side effects is therapy targeted at the diseased organ, following the example of glucocorticoids with the emergence of inhaled and topical treatment.

\section{REFERENCES}

1 Ensom MH. Gender-based differences and menstrual cycle-related changes in specific diseases: implications for pharmacotherapy. Pharmacotherapy 2000;20:523-39.

2 Gissler M, Jarvelin MR, Louhiala P, et al. Boys have more health problems in childhood than girls: follow-up of the 1987 Finnish birth cohort. Acta Paediatr 1999;88:310-14.

3 Tasker RC. Gender differences and critical medical illness. Acta Paediatr 2000;89:621-3.

4 Rewers AEA. Predictors of acute complications with type 1 diabetes. JAMA 2002;287:2511-18.

5 Ninan TK, Russell G. Respiratory symptoms and atopy in Aberdeen schoolchildren: evidence from two surveys 25 years apart. BM 1992;304:873-5.

6 Zannolli R, Morgese G. Does puberty interfere with asthma? Med Hypotheses 1997;48:27-32.

7 Anderson HR, Pottier AC, Strachan DP. Asthma from birth to age 23: incidence and relation to prior and concurrent atopic disease. Thorax 1992;47:537-42. 
8 Venn A, Lewis S, Cooper M, et al. Questionnaire study of effect of sex and age on the prevalence of wheeze and asthma in adolescence. BM 1998;316:1945-6.

9 Skobeloff EM, Spivey WH, Silverman R, et al. The effect of the menstrual cycle on asthma presentations in the emergency department. Arch Intern Med 1996;156:1837-40.

10 Kjellman B, Gustafsson PM. Asthma from childhood to adulthood: asthma severity, allergies, sensitization, living conditions, gender influence and social consequences. Respir Med 2000;94:454-65.

11 Withers NJ, Low L, Holgate ST, et al. The natural history of respiratory symptoms in a cohort of adolescents. Am J Respir Crit Care Med 1998; 158:352-7.

12 Kaur B, Anderson HR, Austin J, et al. Prevalence of asthma symptoms, diagnosis, and treatment in 12-14 year old children across Great Britain (international study of asthma and allergies in childhood, ISAAC UK). BM 1998:316:1 18-24.

13 Shamssain MH, Shamsian N. Prevalence and severity of asthma, rhinitis, and atopic eczema: the north east study. Arch Dis Child 1999;81:313-17.

14 Kuhni CE, Sennhauser FH. The Yentl syndrome in childhood asthma: risk factors for undertreatment in Swiss children. Pediatr Pulmonol 1995; 19:156-60.

15 Rosenthal $\mathbf{M}$, Bain SH, Cramer D, et al. Lung function in white children aged 4 to 19 years: I: Spirometry. Thorax 1993:48:794-802.

16 Hibbert $M$, Lannigan A, Raven J, et al. Gender differences in lung growth. Pediatr Pulmonol 1995;19:129-34.

17 Sly PD, Willet K. Developmental physiology. In: Silverman M, ed. Childhood asthma and other wheezing disorders. Chapman \& Hall Medical, 1995:55-66.

18 Helms PJ. Lung growth: implications for the development of disease. Thorax 1994;49:440-1.

19 Devereux G, Barker RN. Studies of cord blood mononuclear cell responses and allergy: still in their infancy? Clin Exp Allergy 2002; $32: 331-4$

20 Verity CM, Vanheule B, Carswell F, et al. Bronchial lability and skin reactivity in siblings of asthmatic children. Arch Dis Child 1984;59:871-6.

21 Stein RT, Holberg CJ, Morgan WJ, et al. Peak flow variability, methacholine responsiveness and atopy as markers for detecting different wheezing phenotypes in childhood. Thorax 1997:52:946-52

22 Leynaert B, Bousquet J, Henry C, et al. Is bronchial hyperresponsiveness more frequent in women than in men? A population-based study. Am J Respir Crit Care Med 1997;156:1413-20.

23 Xuan W, Marks GB, Toelle BG, et al. Risk factors for onset and remission of atopy, wheeze, and airway hyperresponsiveness. Thorax 2002;57:104-9.

24 Wormald PJ. Age-sex incidence in symptomatic allergies: an excess of females in the child-bearing years. J Hyg (Lond) 1977;79:39-42.

25 Barbee RA, Halonen M, Lebowitz $M$, et al. Distribution of IgE in a community population sample: correlations with age, sex, and allergen skin test reactivity. J Allergy Clin Immunol 1981;68:106-11.

26 Kulig $M$, Tacke $U$, Forster J, et al. Serum lgE levels during the first 6 years of life. J Pediatr 1999;134:453-8.

27 Eliasson $\mathrm{O}$, Scherzer HH, DeGraff AC Jr. Morbidity in asthma in relation to the menstrual cycle. J Allergy Clin Immunol 1986;77:87-94.

28 Tan KS, McFarlane LC, Lipworth BJ. Modulation of airway reactivity and peak flow variability in asthmatics receiving the oral contraceptive pill. Am J Respir Crit Care Med 1997; 155:1273-7.

29 Kalogeromitros D, Katsarou A, Armenaka M, et al. Influence of the menstrual cycle on skin-prick test reactions to histamine, morphine and allergen. Clin Exp Allergy 1995;25:461-6.
30 Hamano N, Terada N, Maesako K, et al. Effect of sex hormones on eosinophilic inflammation in nasal mucosa. Allergy Asthma Proc 1998; 19:263-9

31 Vliagoftis H, Dimitriadou V, Boucher W, et al. Estradiol augments while tamoxifen inhibits rat mast cell secretion. Int Arch Allergy Immunol 1992:98:398-409.

32 Talal N. Sex hormones and immunity. In: Roitt I, ed. Encyclopedia of immunology. Academic Press, 1992:1369-71.

33 Whitacre CC, Reingold SC, O'Looney PA. A gender gap in autoimmunity. Science 1999:283:1277-8.

34 Cutolo $M$, Balleari $E$, Giusti $M$, et al. Sex hormone status of male patients with rheumatoid arthritis: evidence of low serum concentrations of testosterone at baseline and after human chorionic gonadotropin stimulation. Arthritis Rheum 1988;31:1314-17.

35 Lahita RG, Bradlow L, Fishman J, et al. Estrogen metabolism in systemic lupus erythematosus: patients and family members. Arthritis Rheum 1982;25:843-6

36 Ansar SA, Penhale WJWJ, Talal N. Sex hormones, immune responses, and autoimmune diseases. Am J Pathol 1985;121:531-51.

37 Dayan $M$, Zinger $\mathrm{H}$, Kalush $\mathrm{F}$, et al. The beneficial effects of treatment with tamoxifen and anti-oestradiol antibody on experimental systemic lupus erythematosus are associated with cytokine modulations. Immunology 1997;90:101-8.

38 Grossman CJ. Regulation of the immune system by sex steroids. Endocr Rev 1984:5:435-55.

39 Da Silva JA. Sex hormones and glucocorticoids: interactions with the immune system. Ann N Y Acad Sci 1999;876:102-17.

40 Lahita RG. Sex hormones and the immune system-Part 1. Human data. Baillieres Clin Rheumatol 1990:4:1-12.

41 Zhao XJ, McKerr G, Dong Z, et al. Expression of oestrogen and progesterone receptors by mast cells alone, but not lymphocytes, macrophages or other immune cells in human upper airways. Thorax 2001;56:205-11.

42 Cohen JH, Danel L, Cordier G, et al. Sex steroid receptors in peripheral $T$ cells: absence of androgen receptors and restriction of estrogen receptors to OKT8-positive cells. J Immunol 1983;131:2767-71.

43 Milewich L, Kaimal V, Toews GB. Androstenedione metabolism in human alveolar macrophages. J Clin Endocrinol Metab 1983;56:920-4

44 Sthoeger ZM, Chiorazzi N, Lahita RG. Regulation of the immune response by sex hormones. I. In vitro effects of estradiol and testosterone on pokeweed mitogen-induced human B cell differentiation. J Immunol 1988;141:91-8

45 Paavonen T, Andersson LC, Adlercreutz H. Sex hormone regulation of in vitro immune response. Estradiol enhances human $B$ cell maturation via inhibition of suppressor T cells in pokeweed mitogen-stimulated cultures. J Exp Med 1981;154:1935-45.

46 Fox HS, Bond BL, Parslow TG. Estrogen regulates the IFN-gamma promoter. J Immunol 1991;146:4362-7.

47 Piccinni MP, Giudizi MG, Biagiotti R, et al. Progesterone favors the development of human $T$ helper cells producing Th2-type cytokines and promotes both IL-4 production and membrane CD30 expression in established Th 1 cell clones. J Immunol 1995;155:128-33.

48 van Vollenhoven RF, Morabito LM, Engleman EG, et al. Treatment of systemic lupus erythematosus with dehydroepiandrosterone: 50 patients treated up to 12 months. J Rheumatol 1998:25:285-9.

49 Cutolo M, Balleari E, Giusti M, et al. Androgen replacement therapy in male patients with rheumatoid arthritis. Arthritis Rheum 1991;34:1-5.

50 Bizzarro A, Valentini G, Di Martino G, et al. Influence of testosterone therapy on clinical and immunological features of autoimmune diseases associated with Klinefelter's syndrome. J Clin Endocrinol Metab $1987: 64: 32-6$ 